\title{
UTILIZAÇÃO DE 1-METILCICLOPROPENO E RESFRIAMENTO RÁPIDO NA CONSERVAÇÃ̃ DE PÊSSEGOS ${ }^{1}$
}

\author{
LUCIA C. DE B. PINTO², JOSÉ T. JORGE ${ }^{3}$
}

\begin{abstract}
RESUMO: As perdas pós-colheita variam entre os diversos produtos vegetais, porém, de modo geral, entre as frutas e hortaliças, têm-se perdas da ordem de 30 a 50\%. Assim, este trabalho teve como objetivo a aplicação de 1-metilciclopropeno (1-MCP) e de resfriamento rápido com ar forçado (RR) em pêssegos, a fim de avaliar seus efeitos no processo de amadurecimento dessa fruta. Foram feitas análises fisiológicas: perda de massa fresca, firmeza, $\mathrm{pH}$, acidez titulável, sólidos solúveis, razão SS/AT e produção de $\mathrm{CO}_{2}$, e análises sensoriais: cor, textura e sabor. $\mathrm{O}$ experimento foi dividido em duas etapas. Na primeira, testaram-se as concentrações de 30; 60 e $90 \mathrm{~nL} \mathrm{~L}^{-1}$ de 1-MCP aplicadas nas temperaturas de $0{ }^{\circ} \mathrm{C}$ e $20^{\circ} \mathrm{C}$. As frutas não-tratadas com 1-MCP foram denominadas de controle para as duas temperaturas estudadas. $\mathrm{Na}$ segunda, foram conduzidos os tratamentos: armazenamento refrigerado (AR) ou controle, resfriamento rápido com ar-forçado (RR), resfriamento rápido seguido da aplicação do 1-MCP (RR + 1-MCP) e aplicação de 1-MCP (1-MCP). Dentre esses, o tratamento RR + 1-MCP proporcionou frutas mais firmes em relação às frutas do tratamento-controle. A taxa respiratória dos pêssegos submetidos ao RR e ao $\mathrm{RR}+1$-MCP foi reduzida, se comparada à taxa respiratória das frutas do tratamento-controle.
\end{abstract}

PALAVRAS-CHAVE: fruta, armazenamento, qualidade.

\section{THE USE OF 1-METHYLCYCLOPROPENE AND FAST COOLING IN THE PEACH CONSERVATION}

\begin{abstract}
Postharvest losses vary among the different vegetable products. However, among fruits and vegetables the losses generally range from $30 \%$ to $50 \%$. Thus, this paper aimed the application of 1-methylcycloprene (1-MCP) and fast cooling with forced air (PC) on peaches, in order to estimate their effects in the ripening process of this fruit. Physiological analyses were performed, such as loss of fresh mass, firmness, $\mathrm{pH}$, titratable acidity, soluble solids, ratio and $\mathrm{CO}_{2}$ production, as well as sensorial analyses such as color, texture and flavor. The experiment was divided in two phases. In the first one, concentrations of 30, 60, and $90 \mathrm{~nL} / \mathrm{L} \mathrm{1-MCP}$, applied at $0{ }^{\circ} \mathrm{C}$ and $20{ }^{\circ} \mathrm{C}$, were tested. The fruits treated without $1-\mathrm{MCP}$ were denominated control for both temperatures studied. The second phase was composed by the following treatments: cold storage (CS) or control, cooling with forced air (CFA), cooling with forced air followed by 1-MCP application (CFA + 1-MCP) and 1-MCP application (1-MCP). Among these, the CFA + 1-MCP treatment provided more firmness of the fruits in comparison to the control fruits. The respiratory rate of peaches under CFA and CFA + 1-MCP treatments decreased in comparison to the control fruit respiratory rates.
\end{abstract}

KEYWORDS: fruit, storage, quality.

\section{INTRODUÇÃO}

Dados disponíveis no Brasil indicam que parte da produção nacional de frutas e hortaliças é perdida, principalmente após a colheita, por falta de tratamento e manuseio adequados, vulnerabilidade ao ataque de microrganismos e falta de estocagem frigorificada. Tais perdas póscolheita variam de 30 a 50\%, representando descarte aproximado de 15 milhões de toneladas por ano (DI RIENZO, 2001).

\footnotetext{
${ }^{1}$ Extraído da tese de doutorado do primeiro autor.

${ }^{2}$ Eng ${ }^{\text {a }}$ Agrônoma, Doutora pela Faculdade de Engenharia Agrícola, UNICAMP, Campinas - SP, Fone: (0XX19) 3788.1075, lucalore@uol.com.br

${ }^{3}$ Eng $^{\mathrm{o}}$ de Alimentos, Prof. Doutor, FEAGRI/UNICAMP, Campinas - SP.

Recebido pelo Conselho Editorial em: 8-6-2005
}

Aprovado pelo Conselho Editorial em: 19-9-2006 
A preservação de frutas e hortaliças por meio do frio fundamenta-se, sobretudo, no fato de que baixas temperaturas retardam a ação dos fenômenos metabólicos, prolongando por maior tempo a conservação e a qualidade do produto. A respiração destaca-se como o principal fenômeno fisiológico que influencia na conservação e na qualidade das frutas e hortaliças após a colheita. A baixa temperatura diminui a taxa respiratória, além de proporcionar metabolismo mais lento das frutas, aumentando o período de armazenamento. A redução da respiração é de fundamental importância para a manutenção da qualidade pós-colheita das frutas (ROCHA \& SPAGNOL, 1983).

O resfriamento é, geralmente, considerado como a remoção do calor de produtos recémcolhidos visando à manutenção do frescor e do aroma da pré-colheita. $\mathrm{O}$ termo resfriamento rápido implica remoção do calor antes de o produto ser transportado para mercados distantes, processado ou armazenado. O resfriamento rápido é, geralmente, feito separado, dentro de poucas horas ou até mesmo minutos. Entretanto, o resfriamento na câmara de armazenagem não é considerado resfriamento rápido (ASHRAE, 1998).

Existem quatro métodos principais de remoção rápida do calor dos produtos hortícolas, dependendo do meio refrigerante utilizado. São eles: o resfriamento com ar forçado, com água gelada, com gelo e a vácuo (CORTEZ et al., 2002; ASHRAE, 1998).

O resfriamento em água tem sido muito recomendado e usado nos Estados Unidos, onde os resultados parecem ser benéficos para o pêssego (HARDENBURG et al., 1986). Entretanto, no Brasil, parece que esse método não tem apresentado bons resultados, pois tem favorecido o ataque de patógenos (BRACKMANN et al., 2001).

Além do uso da refrigeração na conservação pós-colheita de frutas e hortaliças, técnicas de remoção de etileno têm sido empregadas, como, por exemplo, o uso do gás 1-metilciclopropeno (1MCP). Acredita-se que o 1-MCP seja antagonista do etileno. Ao ligar-se ao sítio de recepção do etileno na célula, o 1-MCP interfere na ação do etileno endógeno ou exógeno, diminuindo, assim, sua ação (ARGENTA et al., 2000).

O 1-metilciclopropeno é um produto inovador que interfere na ação do etileno em frutas armazenadas. É apresentado na forma de pó e, com a adição de solução neutra ou água, libera o ingrediente ativo 1-metilciclopropeno, na forma de gás (ROHM AND HAAS COMPANY, 2000).

Desse modo, neste trabalho, teve-se o objetivo de determinar os efeitos do gás 1metilciclopropeno (1-MCP) aplicado a $0{ }^{\circ} \mathrm{C}$ e $20^{\circ} \mathrm{C}$, e do resfriamento rápido com ar forçado na qualidade e conservação de pêssegos.

\section{MATERIAL E MÉTODOS}

$\mathrm{O}$ experimento foi dividido em duas etapas. $\mathrm{Na}$ primeira etapa, foram testadas diferentes concentrações de 1-MCP aplicadas nas temperaturas $0{ }^{\circ} \mathrm{C}$ e $20^{\circ} \mathrm{C}$ e, na etapa seguinte, foi feita uma combinação entre o melhor tratamento obtido na primeira etapa com o resfriamento rápido com ar forçado.

\section{Etapa 1}

Foi desenvolvida com pêssegos da cultivar Aurora I, provenientes do município de Atibaia $\mathrm{SP}$, distante de Campinas, do local do experimento, $75 \mathrm{~km}$.

Os pêssegos foram colhidos no período da manhã. Após a colheita, as frutas passaram por classificação de tamanho, sendo selecionados os pêssegos tipo 10, ou seja, 10 unidades da fruta por caixa. Os pêssegos ficaram armazenados em caixas de papelão com dimensões de 225 x 205 x $60 \mathrm{~mm}$ e área de abertura de $2,6 \%$.

Foram avaliadas diferentes concentrações de 1-MCP aplicado nas temperaturas $0{ }^{\circ} \mathrm{C}$ e $20^{\circ} \mathrm{C}$, durante $12 \mathrm{~h}$, buscando definir o melhor tratamento na conservação pós-colheita de pêssegos.

Câmaras herméticas foram construídas para a aplicação do produto comercial SmartFresh (0,14\% i.a.), utilizando-se de caixas plásticas de $350 \mathrm{~L}$ com tampa de acrílico para melhor 
visualização, com vedação de borracha. Na lateral dessa caixa, foi colocado um par de luvas de borracha, devidamente preso, para facilitar o manuseio do gás 1-MCP. Esse par de luvas possibilitou a liberação do gás 1-MCP dentro da câmara com a tampa já fechada, evitando trocas do ar do interior com o exterior da câmara.

Para a obtenção do 1-MCP na forma de gás, o produto comercial SmartFresh - que se apresenta na forma de pó - foi dissolvido em água deionizada à temperatura ambiente. Esse produto foi colocado em recipiente hermético de vidro de $80 \mathrm{~mL}$, onde foi misturado a $3 \mathrm{~mL}$ de água, injetada com o auxílio de seringa. A mistura foi, posteriormente, agitada até total dissolução. Esse recipiente foi colocado dentro da câmara hermética e, em seguida, colocaram-se os pêssegos, e a câmara foi fechada. Com o auxílio do par de luvas fixado na câmara hermética, foi possível abrir o recipiente contendo 1-MCP já com a câmara vedada. As frutas do tratamento-controle foram mantidas nas mesmas condições, porém sem tratamento com 1-MCP.

Com o auxílio de um termômetro de polpa, fizeram-se leituras da temperatura da polpa de algumas frutas até atingirem a temperatura estipulada para a aplicação do gás.

Foram testados os tratamentos: $0 \mathrm{~nL} \mathrm{~L}^{-1}$ de $1-\mathrm{MCP}$ a $0{ }^{\circ} \mathrm{C}$ (controle a $0{ }^{\circ} \mathrm{C}$ ); $30 \mathrm{~nL} \mathrm{~L}^{-1}$ de 1 $\mathrm{MCP}$ a $0{ }^{\circ} \mathrm{C} ; 60 \mathrm{~nL} \mathrm{~L}^{-1}$ de $1-\mathrm{MCP}$ a $0{ }^{\circ} \mathrm{C} ; 90 \mathrm{~nL} \mathrm{~L}{ }^{-1}$ de $1-\mathrm{MCP}$ a $0{ }^{\circ} \mathrm{C} ; 0 \mathrm{~nL} \mathrm{~L}{ }^{-1}$ de $1-\mathrm{MCP}$ a $20{ }^{\circ} \mathrm{C}$ (controle a $20^{\circ} \mathrm{C}$ ); $30 \mathrm{~nL} \mathrm{~L}^{-1}$ de $1-\mathrm{MCP}$ a $20^{\circ} \mathrm{C} ; 60 \mathrm{~nL} \mathrm{~L}^{-1}$ de $1-\mathrm{MCP}$ a $20{ }^{\circ} \mathrm{C}$, e $90 \mathrm{~nL} \mathrm{~L} \mathrm{~L}^{-1}$ de 1 MCP a $20^{\circ} \mathrm{C}$.

Para as concentrações 30; 60 e $90 \mathrm{~nL} \mathrm{~L}^{-1}$, foram pesados, respectivamente, 0,0168 g, $0,0336 \mathrm{~g}$ e 0,0504 g do produto comercial SmartFresh, por câmara de aplicação, de acordo com o fabricante.

Um lote de pêssego atingiu $20^{\circ} \mathrm{C}$, após permanecer $5 \mathrm{~h}$ em uma câmara convencional a $20^{\circ} \mathrm{C}$. A partir daí, esses pêssegos foram acondicionados nas câmaras herméticas sob exposição ao 1-MCP por um período de $12 \mathrm{~h}$, após as quais, os pêssegos foram retirados das câmaras herméticas e armazenados em câmara fria a $0 \pm 1^{\circ} \mathrm{C}$ e UR entre 98 e $99 \%$, por um período de cinco semanas.

Por volta de $19 \mathrm{~h}$ de armazenamento em uma câmara convencional a $0{ }^{\circ} \mathrm{C}$, outro lote de pêssego alcançou essa temperatura e foi exposto ao 1-MCP por um período de $12 \mathrm{~h}$, na câmara hermética. Após esse período, as frutas foram armazenadas em câmara fria a $0 \pm 1{ }^{\circ} \mathrm{C}$ e UR entre 98 e $99 \%$, juntamente com os pêssegos que já haviam sido expostos ao gás $1-\mathrm{MCP}$ a $20^{\circ} \mathrm{C}$.

\section{Etapa 2}

Nesta etapa da fase experimental, foram utilizados pêssegos da cultivar Natal, provenientes do mesmo produtor citado na primeira etapa.

Os pêssegos foram colhidos no período da manhã e, logo após a colheita, passaram por classificação de tamanho, sendo selecionados os pêssegos tipo 12, ou seja, 12 unidades da fruta por caixa. Essa caixa foi a mesma que se utilizou na etapa anterior, porém com maior número de frutas por caixa, em função de as frutas serem pouco menores.

Foi realizada uma combinação entre o tratamento da primeira etapa, que apresentou melhor conservação dos pêssegos, com o resfriamento rápido com ar forçado. Assim, nessa segunda etapa, testou-se a concentração $90 \mathrm{~nL} \mathrm{~L}^{-1}$ de $1-\mathrm{MCP}$ aplicado a $0{ }^{\circ} \mathrm{C}$, com o resfriamento rápido em ar forçado.

Dentro da câmara fria convencional, foi montado o sistema de resfriamento com ar forçado com o auxílio de um ventilador centrífugo, o qual tem a função de forçar o ar frio que sai do evaporador a passar entre as caixas de pêssegos, e entre as caixas e as frutas, refrigerando-as. Com o auxílio de termopares inseridos nas frutas, foi possível acompanhar o resfriamento dos pêssegos por meio do Programa AqDados (LYNX, 1984). O resfriamento foi realizado com o tempo de $7 / 8$ de resfriamento.

Para a determinação do tempo de resfriamento, foram usados os dados obtidos a partir das temperaturas lidas nas frutas e calculada a Taxa Adimensional de Temperatura (TAT). Quando a TAT for igual a 0,125 , as frutas atingem o tempo de 7/8 de resfriamento, ou seja, o tempo 
necessário para reduzir a 1/8 a diferença entre a temperatura inicial do produto e a temperatura do meio de resfriamento, conforme eq.(1):

$$
\mathrm{TAT}_{7 / 8}=(\mathrm{Tc}-\mathrm{Ta}) /(\mathrm{Ti}-\mathrm{Ta})=0,125
$$

em que,

TAT - taxa adimensional de temperatura;

Tc - temperatura no centro da fruta, ${ }^{\circ} \mathrm{C}$;

$\mathrm{Ta}$ - temperatura do ar de resfriamento, ${ }^{\circ} \mathrm{C}$, e

$\mathrm{Ti}$ - temperatura inicial da fruta, ${ }^{\circ} \mathrm{C}$.

O fluxo de ar utilizado foi de $8 \mathrm{~L} \mathrm{~s}^{-1}$. Na literatura, há indicações de que a taxa de ar deve estar entre 1 e $6 \mathrm{~L} \mathrm{~s}^{-1}$ por $\mathrm{kg}$ de produto (FRASER, citado por TERUEL et al., 2002); entretanto, esse valor acima do recomendado não afetou a perda de massa fresca das frutas.

Outro lote de pêssego, após sofrer o resfriamento rápido, foi acondicionado em câmara hermética sob exposição do gás 1-MCP por um período de $12 \mathrm{~h}$. Após esse período de exposição ao gás, os pêssegos foram retirados da câmara hermética e armazenados em câmara fria a $0 \pm 1^{\circ} \mathrm{C}$ e UR entre 80 e $98 \%$, juntamente com as frutas que sofreram o resfriamento rápido.

Depois de $16 \mathrm{~h}$ de armazenamento convencional, na temperatura de $0{ }^{\circ} \mathrm{C}$, outro lote de pêssego foi exposto ao gás 1-MCP por $12 \mathrm{~h}$ na câmara hermética. Após esse período, as frutas foram armazenadas em câmara fria a $0 \pm 1{ }^{\circ} \mathrm{C}$ e UR entre 80 e $98 \%$, durante cinco semanas.

Dessa forma, foram aplicados os tratamentos: $\mathrm{RR}$; $\mathrm{RR}+90 \mathrm{~nL} \mathrm{~L} \mathrm{~L}^{-1}$ de $1-\mathrm{MCP}$ a $0{ }^{\circ} \mathrm{C}$; $90 \mathrm{~nL} \mathrm{~L} \mathrm{~L}^{-1}$ de $1-\mathrm{MCP}$ a $0{ }^{\circ} \mathrm{C}$ e AR (controle).

\section{Avaliações fisiológicas e sensoriais}

As avaliações fisiológicas e sensoriais foram feitas semanalmente, com exceção da análise de $\mathrm{CO}_{2}$, que foi realizada aos $0 ; 2 ; 4 ; 6 ; 9 ; 12 ; 15 ; 22 ; 29$ e 36 dias de armazenamento.

\section{Fisiológicas}

1. Perda de massa fresca - as frutas foram pesadas em balança analítica, e os resultados foram obtidos através da relação entre a massa inicial de cada fruta no dia da aplicação do tratamento e a sua massa ao longo das avaliações, relação esta expressa em porcentagem de perda de massa fresca. Esses pêssegos foram numerados e mantidos intactos ao longo do experimento.

2. Firmeza - foi determinada utilizando-se do Texturômetro modelo TA - XT2i (Stable Micro Systems), procedendo-se a uma leitura na região equatorial das frutas, sendo os resultados expressos em newton (N) (MEDLICOTT, 1985).

3. Produção de $\mathrm{CO}_{2}$ - os pêssegos foram colocados em recipientes herméticos e, após uma hora de acondicionamento a $0{ }^{\circ} \mathrm{C}$ em estufa tipo BOD, foram determinadas as concentrações de $\mathrm{CO}_{2}$ por cromatografia gasosa. Para essa análise, foram coletadas alíquotas de $1 \mathrm{~mL}$ de gás, utilizando uma seringa hermética. A análise foi feita em cromatógrafo a gás Varian 3400, com detector de condutividade térmica. A concentração de $\mathrm{CO}_{2}$, que é proporcional à área do pico obtido após injeção da amostra no cromatógrafo, foi calculada em função da variação do peso das amostras dos tratamentos (PADULA et al., 1989). (1985).

4. $\mathrm{pH}$ - foi determinado por potenciometria, de acordo com o INSTITUTO ADOLFO LUTZ

5. Acidez titulável (AT) - foi expressa em gramas de ácido cítrico por $100 \mathrm{~g}$ de polpa, sendo determinada por meio da titulação de $10 \mathrm{~g}$ de polpa homogeneizada e diluída até $100 \mathrm{~mL}$ de água destilada, com solução padronizada de hidróxido de sódio $0,1 \mathrm{~N}$, até o peagômetro atingir 8,1 (AOAC, 1997).

6. Sólidos solúveis (SS) - foram obtidos por meio de leitura direta em refratômetro e expressos em ${ }^{\circ}$ Brix, conforme recomendações feitas pelo INSTITUTO ADOLFO LUTZ (1985). 
7. Razão (SS/AT) - foi expressa por meio da relação entre os teores de sólidos solúveis e a acidez titulável.

\section{Sensoriais}

Foram feitas por um grupo de 12 provadores treinados, utilizando o Teste de Ordenação. Os julgadores foram solicitados a ordenar as amostras (colocando-as em ordem crescente) quanto à intensidade de determinado atributo. Os julgadores avaliaram as amostras quanto à cor, firmeza e sabor (FERREIRA et al., 2000).

\section{Análise estatística}

$\mathrm{Na}$ etapa 1, foi empregado o delineamento inteiramente casualizado (DIC), com oito tratamentos e três repetições, em esquema fatorial $2 \times 4 \times 6$, em que se estudaram temperatura, concentração do 1-MCP e tempo de armazenamento. Na etapa 2, também se utilizou o DIC, com quatro tratamentos e quatro repetições, em esquema fatorial 4x6 (tratamentos e tempo de armazenamento). Em ambas as etapas, foi utilizado o teste de Tukey, a 5\%, para a comparação entre as médias.

\section{RESULTADOS E DISCUSSÃO}

\section{Etapa 1}

$\mathrm{Na}$ análise de produção de $\mathrm{CO}_{2}$, ocorreu interação entre temperatura e concentração do 1$\mathrm{MCP}$, de forma que as diferentes concentrações tiveram diferença significativa apenas na temperatura de $0{ }^{\circ} \mathrm{C}$, no final do período de armazenamento. A concentração $90 \mathrm{~nL} \mathrm{~L}^{-1}$ de $1-\mathrm{MCP}$ apresentou a mais baixa produção de $\mathrm{CO}_{2}$, diferindo estatisticamente $(\mathrm{P}<0,05)$ da concentração $30 \mathrm{~nL} \mathrm{~L}^{-1}$ e do controle, conforme Figura 1.

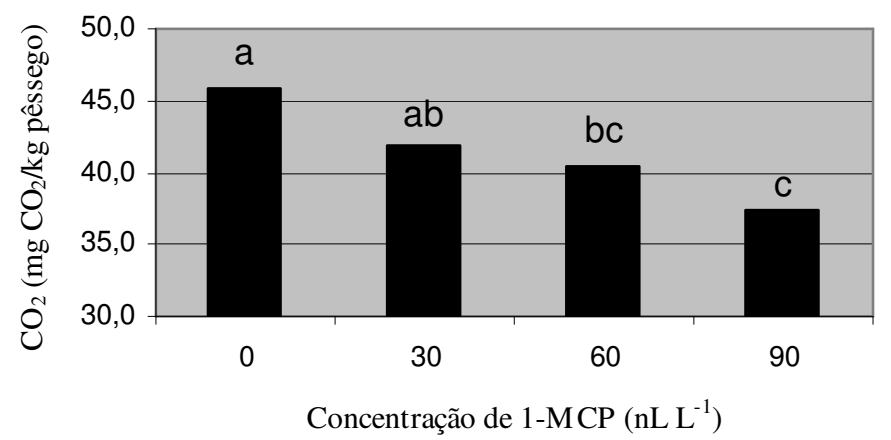

- Letras iguais significam que os tratamentos não diferem estatisticamente, a 5\%, pelo teste Tukey.

FIGURA 1. Produção de $\mathrm{CO}_{2}$ de pêssegos cv. Aurora I tratados com 1-MCP a $0{ }^{\circ} \mathrm{C}$.

Essa redução na taxa respiratória das frutas tratadas com $90 \mathrm{~nL} \mathrm{~L}^{-1}$ de $1-\mathrm{MCP}$ a $0{ }^{\circ} \mathrm{C}$ pode explicar a maior conservação dessas frutas. De acordo com KADER (1992), a capacidade de conservação de um produto hortícola está inversamente relacionada à taxa respiratória e, em muitos casos, à taxa de produção do etileno.

A redução na taxa respiratória de frutas tratadas com 1-MCP foi reportada em trabalhos anteriores (BRACKMANN et al., 2004; FAN et al., 2000; ABDI et al., 1998).

Nas demais análises, não houve efeito significativo das concentrações de 1-MCP aplicadas nas temperaturas de $0{ }^{\circ} \mathrm{C}$ e $20^{\circ} \mathrm{C}$.

\section{Etapa 2}

$\mathrm{Na}$ análise de firmeza, o tratamento $\mathrm{RR}+1-\mathrm{MCP}$ exibiu os mais altos valores, porém foi estatisticamente $(\mathrm{P}<0,05)$ superior apenas ao tratamento-controle (Figura 2$)$ no final do período estudado. A maior firmeza nas frutas tratadas com $\mathrm{RR}+1-\mathrm{MCP}$ está provavelmente associada à união das técnicas de resfriamento rápido com ar forçado, com o bloqueador de ação do etileno. 
Dessa forma, os pêssegos que receberam esse tratamento, apresentam potencial de conservação maior quando comparados às frutas do tratamento-controle.

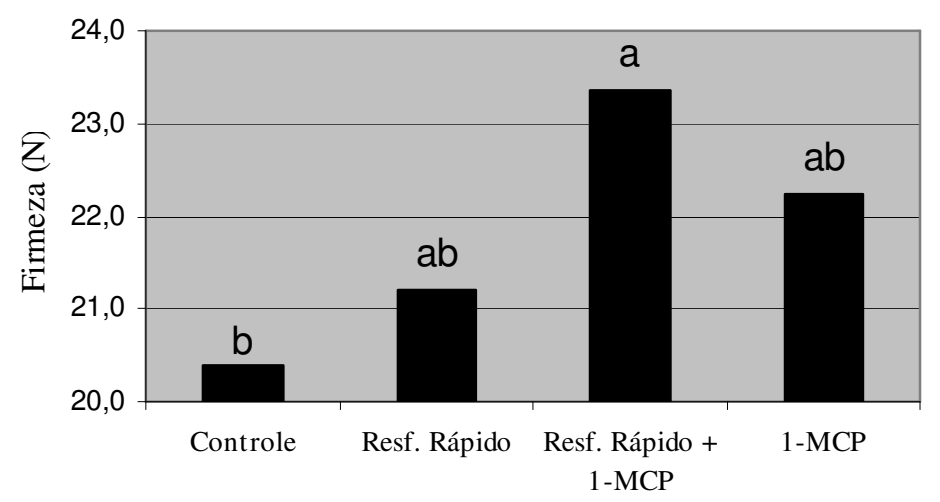

- Letras iguais significam que os tratamentos não diferem estatisticamente, a 5\%, pelo teste Tukey.

FIGURA 2. Firmeza de pêssegos cv. Natal.

A retenção da firmeza de frutas tratadas com 1-MCP foi relatada por ABDI et al. (1998). No mesmo sentido, GIRARDI et al. (2003) constataram que a perda da firmeza em pêssegos cv. Chiripá ocorre de forma mais lenta nas frutas tratadas com 1-MCP, apresentando firmeza de polpa significativamente superior à testemunha.

Quanto ao teor de sólidos solúveis, o tratamento-controle apresentou maior teor de sólidos solúveis, diferindo dos tratamentos RR+1-MCP e 1-MCP, após cinco semanas de armazenamento (Figura 3).

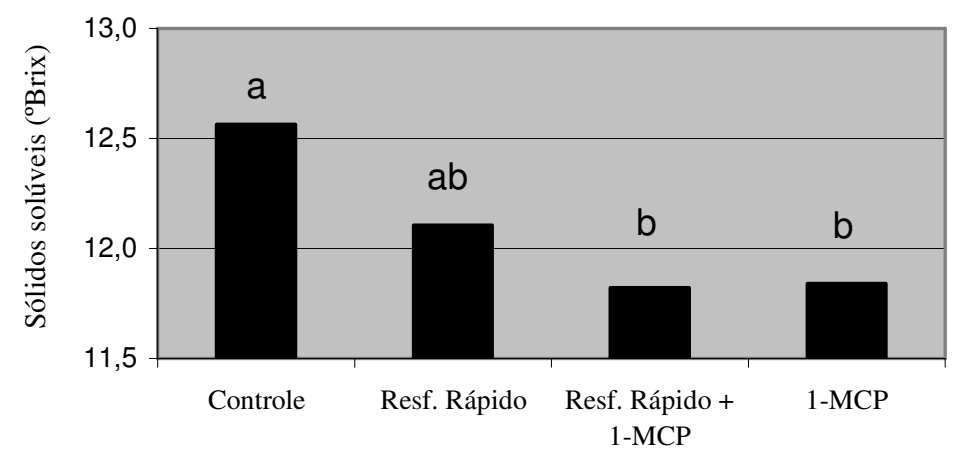

- Letras iguais significam que os tratamentos não diferem estatisticamente, a 5\%, pelo teste Tukey.

FIGURA 3. Valores de sólidos solúveis de pêssegos cv. Natal.

Assim, pode-se verificar que os tratamentos RR +1-MCP e 1-MCP exibiram os mais baixos valores dos sólidos solúveis comparados ao controle, sugerindo, portanto, menor atividade metabólica nessas frutas. Diversos autores não encontraram efeito do 1-MCP sobre o teor de sólidos solúveis em frutas (BRACKMANN et al., 2003; GIRARDI et al., 2003; NEVES et al., 2003). Por outro lado, SARRIA (2003), em estudos com figos, relatou que o teor de sólidos solúveis foi mais baixo submetido ao resfriamento rápido em relação aos resfriados lentamente.

Avaliando-se a produção de $\mathrm{CO}_{2}$ (Figura 4), entre os tratamentos aplicados, o controle apresentou maior taxa de produção de $\mathrm{CO}_{2}$, sendo estatisticamente igual $(\mathrm{P}<0,05)$ ao tratamento com 1-MCP. Esse dado não era esperado, visto que o 1-MCP, aplicado nas frutas em pós-colheita, se liga ao sítio de ligação na membrana da célula da fruta, fixando-se de maneira preferencial em relação ao etileno. Desse modo, o 1-MCP interfere no modo de ação do etileno, resultando em menor produção de $\mathrm{CO}_{2}$. Esse resultado pode ter sofrido influência das diferentes cultivares 
estudadas, uma vez que, na primeira etapa, a cultivar Aurora I apresentou menor produção de $\mathrm{CO}_{2}$, quando aplicado o 1-MCP.

Esse resultado difere de alguns autores como NEVES et al. (2003) e FAN et al. (2000), os quais, trabalhando, respectivamente, com kiwis e damascos tratados com 1-MCP, observaram reduzidas taxas respiratórias nessas frutas.

Por outro lado, o tratamento RR apresentou a mais baixa produção de $\mathrm{CO}_{2}$ sem, entretanto, diferir do tratamento RR +1-MCP. Esses tratamentos apresentaram menor taxa respiratória nas frutas e, portanto, maior conservação pós-colheita das mesmas (Figura 4).

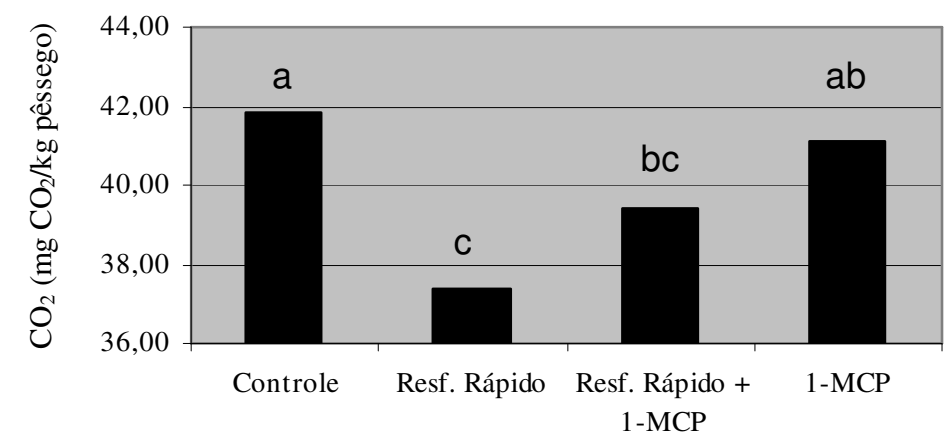

- Letras iguais significam que os tratamentos não diferem estatisticamente, a 5\%, pelo teste Tukey.

FIGURA 4. Produção de $\mathrm{CO}_{2}$ de pêssegos cv. Natal nos tratamentos aplicados.

BRACKMANN et al. (2004) afirmam que a redução na taxa respiratória de maçãs cv. Gala, tratadas com 1-MCP, pode ser explicada pela redução da síntese de novos sítios receptores devido à baixa temperatura durante o armazenamento. No mesmo sentido, KLUGE et al. (2002) relataram que o resfriamento rápido reduz a atividade respiratória de frutas.

Desse modo, a taxa respiratória das frutas foi diminuída com a aplicação do resfriamento rápido e do resfriamento rápido em associação com 1-MCP, comparada com a taxa respiratória das frutas do tratamento-controle.

Os demais parâmetros avaliados não sofreram influência dos tratamentos.

\section{CONCLUSÕES}

As concentrações 60 e $90 \mathrm{~nL} \mathrm{~L}{ }^{-1}$ de 1 -MCP aplicadas a $0{ }^{\circ} \mathrm{C}$ promoveram menor produção de $\mathrm{CO}_{2}$ em pêssegos cultivar Aurora I em comparação às frutas do tratamento-controle (sem aplicação de 1-MCP), após cinco semanas de armazenamento, indicando que esses tratamentos promoveram maior conservação dessas frutas.

As diferentes concentrações do 1-MCP aplicadas em diferentes temperaturas não interferiram nos parâmetros perda de massa fresca, firmeza, $\mathrm{pH}$, acidez titulável, sólidos solúveis, razão SS/AT e também na análise sensorial de pêssegos cultivar Aurora I.

A associação das técnicas de resfriamento rápido com o 1-MCP proporcionou pêssegos (cultivar Natal) mais firmes, com baixos níveis de sólidos solúveis, além de reduzida taxa respiratória, comparados com as frutas do tratamento-controle, as quais foram resfriadas lentamente na câmara fria.

\section{REFERÊNCIAS}

ABDI, N.; McGLASSON, W.B.; HOLFORD, P.; WILLIAMS, M.; MIZRAHI, Y. Responses of climateric and suppressed-climateric plums to treatment with propylene and 1-methylcyclopropene. Postharvest Biology and Technology, Amsterdam, v.14, n.1, p. 29-39, june, 1998. 
ARGENTA, L.C.; MATTHEIS, J.P.; FAN, X. Controle do amadurecimento de frutas manipulação da ação do etileno com 1-metilciclopropeno para preservação pós-colheita de maçãs e peras. In: CONGRESSO BRASILEIRO DE FRUTICULTURA, 16., 2000, Fortaleza. Anais... Fortaleza: Sociedade Brasileira de Fruticultura, 2000. p.236-43.

ASHRAE HANDBOOK. Methods of precooling fruits, vegetables, and cut flowers. In: Refrigeration systems and applications. Atlanta: SI Edition, 1998. cap.14, p.1-10.

BRACKMANN, A.; SESTARI, I.; STEFFENS, C.A.; GIEHL, R.F.H. Qualidade de maçã cv. Gala tratada com 1-metilciclopropeno. Ciência Rural, Santa Maria, v.34, n.5, p.1415-20, 2004.

BRACKMANN, A.; FREITAS, S.T.; MELLO, A.M.; STEFFENS, C.A. Aplicação de 1-MCP em caqui 'quioto' armazenado sob refrigeração e atmosfera controlada. Revista Brasileira de Fruticultura, Jaboticabal, v.25, n.1, p.42-44, 2003.

BRACKMANN, A.; HUNSCHE, M.; CERETTA, M. Pré-resfriamento e absorção de etileno durante o armazenamento de pêssegos cv. Chiripá. Revista Brasileira de Armazenamento, Viçosa, v.26, n.1, p.12-15, 2001.

CORTEZ, L.A.B.; CASTRO, L.R.; VIGNEAULT, C. Resfriamento rápido a ar: métodos da câmara frigorífica e do ar forçado. In: CORTEZ, L.A.B.; HONÓRIO, S.L.; MORETTI, C.L. (Org.) et al. Resfriamento de frutas e hortaliças. Brasília: EMBRAPA, 2002. cap.11, p.231-72.

DI RIENZO, C. A importância das câmaras frias na hortifruticultura. Tecnologia da Refrigeração, São Paulo, n.5, p.16-22, 2001.

FAN, X.; ARGENTA, L.; MATTHEIS, J. P. Inhibition of ethylene action by 1methylcycloporpene prolongs storage life of apricots. Postharvest Biology and Technology, Amsterdam, v.20, n.2, p. 135-42, 2000.

FERREIRA, V.L.P.; ALMEIDA, T.C.A; PETTINELLI, M.L.C. de V.; SILVA, M.A.A.P.; CHAVES, J.B.P.; BARBOSA, E.M. de M. Análise sensorial: testes discriminativos e afetivos. Campinas: SBCTA, 2000. 127 p. (Manual - Série Qualidade).

GIRARDI, C.L.; MARTINS, C.R.; PARUSSOLO, A.; TOMASI, R.J.; CORRENT, A.R.; ROMBALDI, C.V. Efeito da aplicação de 1-metilciclopropeno na conservação da qualidade de pêssegos (Prunus persica L.), cultivar Chiripá. Revista Brasileira de Agrociência, Pelotas, v.9, n.2, p.157-61, 2003.

HARDENBURG, R.E.; WATADA, A.E.; WANG, C.Y. The commercial storage of fruits, vegetables, and florist and nursery stocks. Washington: US Department of Agriculture, 1986. $136 \mathrm{p}$.

INSTITUTO ADOLFO LUTZ. Normas analíticas: métodos físicos e químicos para análise de alimentos. 3.ed. São Paulo: Instituto Adolfo Lutz, 1985. 533 p.

KADER, A.A. Postharvest technology of horticultural crops. Davis: University of California, 1992. $296 \mathrm{p}$.

KLUGE, R.A.; JACOMINO, A.P.; OJEDA, R.M.; BRACKMANN, A. Inibição do amadurecimento de abacate com 1-metilciclopropeno. Pesquisa Agropecuária Brasileira, Brasília, v.37, n.7, p.895-901, 2002.

LYNX. AqDados. São Paulo: Lynx Tecnologia Eletrônica, 1984.

MEDLICOTT, A.P. Mango fruit ripening and the effects of maturity, temperature and gases. Horticultural Sciences, Stuttgart, v.8, n.1, p.76-7, 1985.

NEVES, L.C.; CORRENT, A.; MARINI, L.; LUCCHETTA, L.; ZANUZZO, M.R.; GONÇALVES, E.D.; ZANATTA, J.; CANTILLANO, R.; ROMBALDI, C.V. Atmosfera modificada e 1-metilciclopropeno na conservação pós-colheita de kiwis cv. Bruno. Revista Brasileira de Fruticultura, Jaboticabal, v.25, n.3, p.390-3, 2003.

PADULA, M.; SARANTÓPOLUS, C.I.G.L.; ARDITO, E.F.G. Embalagens plásticas: controle de qualidade. Campinas: ITAL/SBCTA, 1989. 202 p. 
ROCHA, J.L.V. da; SPAGNOL, W.A. Frutas e hortaliças. In: VAN'DENDER, A.G.F. et al. Armazenamento de gêneros e produtos alimentícios. São Paulo: Secretaria da Indústria, Comércio, Ciência e Tecnologia, 1983. p. 227-72.

ROHM AND HAAS COMPANY. 1 -Metilciclopropeno (1-MCP). 2000, 17 p. (Boletim Técnico). SARRIA, S.D. Resfriamento rápido e armazenamento refrigerado do figo (Ficus carica L.) 'Roxo de Valinhos' e seus efeitos na qualidade da fruta. 2003. $150 \mathrm{f}$. Tese (Doutorado em Tecnologia Pós-Colheita) - Faculdade de Engenharia Agrícola, Universidade Estadual de Campinas, Campinas, 2003.

TERUEL, B.; CORTEZ, L.; LEAL, P.; NEVES FILHO, L. Resfriamento de banana-prata com arforçado. Revista Brasileira de Fruticultura, Jaboticabal, v.24, n.1, p.142-6, 2002. 